\title{
An Integrated Product and Process Model
}

\author{
Prof. Dr.-Ing. Dr.-Ing. E.h. H. K. Tönshoff
}

Dipl.-Ing. M. Zwick

Institute for Production Engineering and Machine Tools (IFW)

Schlosswender Str. 5, D-30161 Hannover, Germany

Telephone: +49511 762-4855

Fax: $+49511762-4015$

E-mail: zwick@mail.ifw.uni-hannover.de

\begin{abstract}
The Integrated Product and Process Model offers the possibility of mapping product specifications to existing production systems. In reversal product developers may be enabled to recognise production system limitations in product development. This paper presents the concept of the Integrated Product and Process Model.
\end{abstract}

\section{Keywords}

Product model, process model, STEP 


\section{INTRODUCTION}

Market dynamic is rapidly increasing and customers are demanding higher product quality, individual design and shorter delivery times. Producing companies have to meet these requirements to keep a strong market position. Consequently, production systems have to be adapted continuously to the production of different variants or to new product types. Additionally product development should recognise production system limitations by designing new products on a very early stage. Due to the isolated adaptation of the production system in different sections only sub-optima are reached. The overall operating capacity and efficiency of the production system will currently not be assessed.

For this reason an integrated tool will be developed for the Evaluation and Analysis of production SYstems for optimised CONfiguration and implementation (EASYCON).

The evaluation of manufacturing systems will be executed on different levels from single machines to production lines. The evaluation results will be used for:

- Recognition of manufacturing limitations in product development

- Benchmarking of production systems

- Development of control strategies to improve the manufacturing system's performance

- Development of planning strategies to generate alternative production systems configurations

This paper presents the Integrated Product and Process Model as the core of the above mentioned system.

\section{THE INTEGRATED PRODUCT AND PROCESS MODEL}

The Integrated Product and Process Model (IPPM) integrates product and process specifications. Also the IPPM allows to connect and to allocate products to processes. Therefore the IPPM consists of a Product Model PDM, a Process Model PCM and an Overall Process Schema OPS (see Figure 1) 


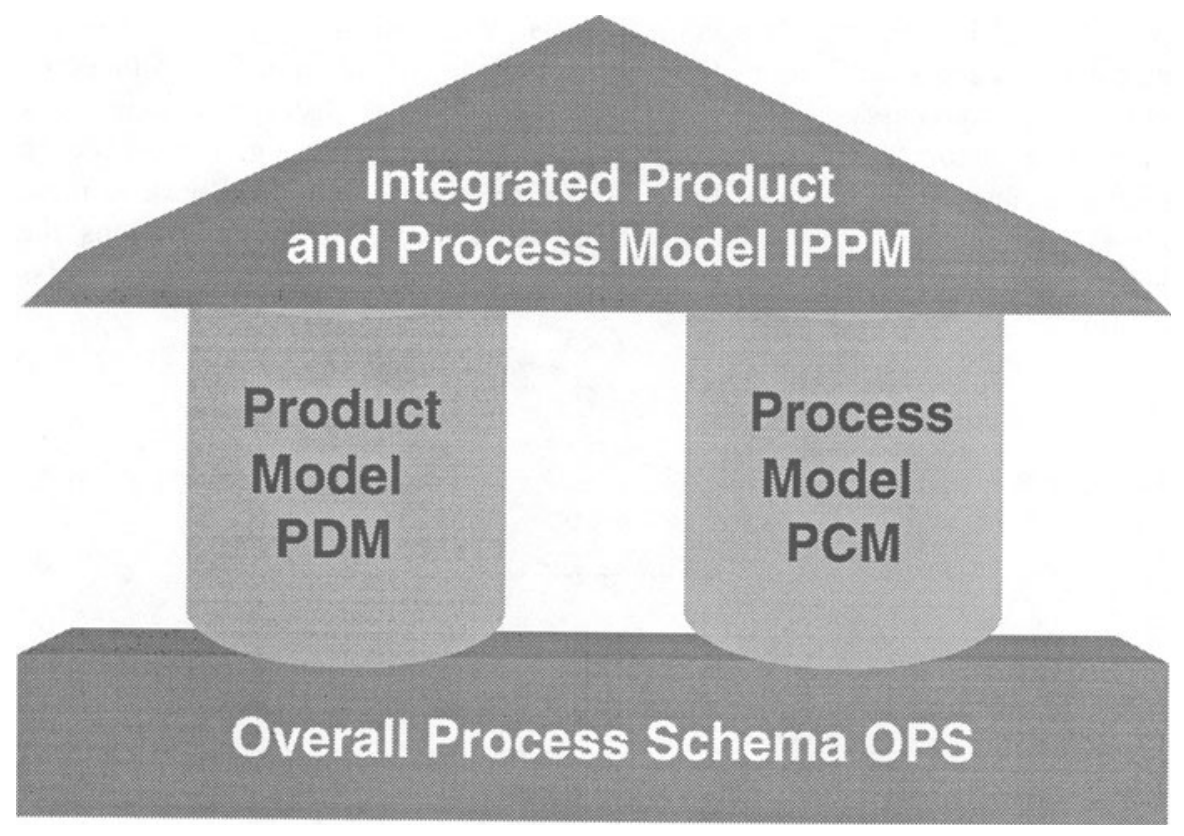

Figure 1: The Integrated Product and Process Model (IPPM)

Product Model (PDM):

The PDM integrates all different information describing a product. This information could be parameters, text information, customer demands and others.

\section{Process Model (PCM):}

The PCM includes information about production processes and machines. Also it represents specific product related process information. Due to the hierarchical organisation of the model, it is possible to implement production systems configurations.

Overall Process Schema (OPS):

The OPS offers the possibility to link products to production processes. This general schema is dedicated to all branches, but all users have the possibility to add company specific processes.

\section{INTERACTION OF PRODUCT AND PROCESS MODEL}

Figure 2 shows the general interaction of the Product and the Process Model. The Product Model consists of the product specification. Input for this product specification are in a first stage the customer demands and the related performance specification describing the proposed functionality of the product. The core of the 
process model is the process specification which is built by production data and machine supplier specifications. Both specifications are the input for the mapping of products to processes. Additionally parameters of the product specification work as control factors for this mapping. These parameters are e.g. manufacturing tolerances and quality aspects. The results of the mapping are lead back as input for new product and process specifications. After several development loops, the product may be realised in accordance to an 'optimal' product and process relation.

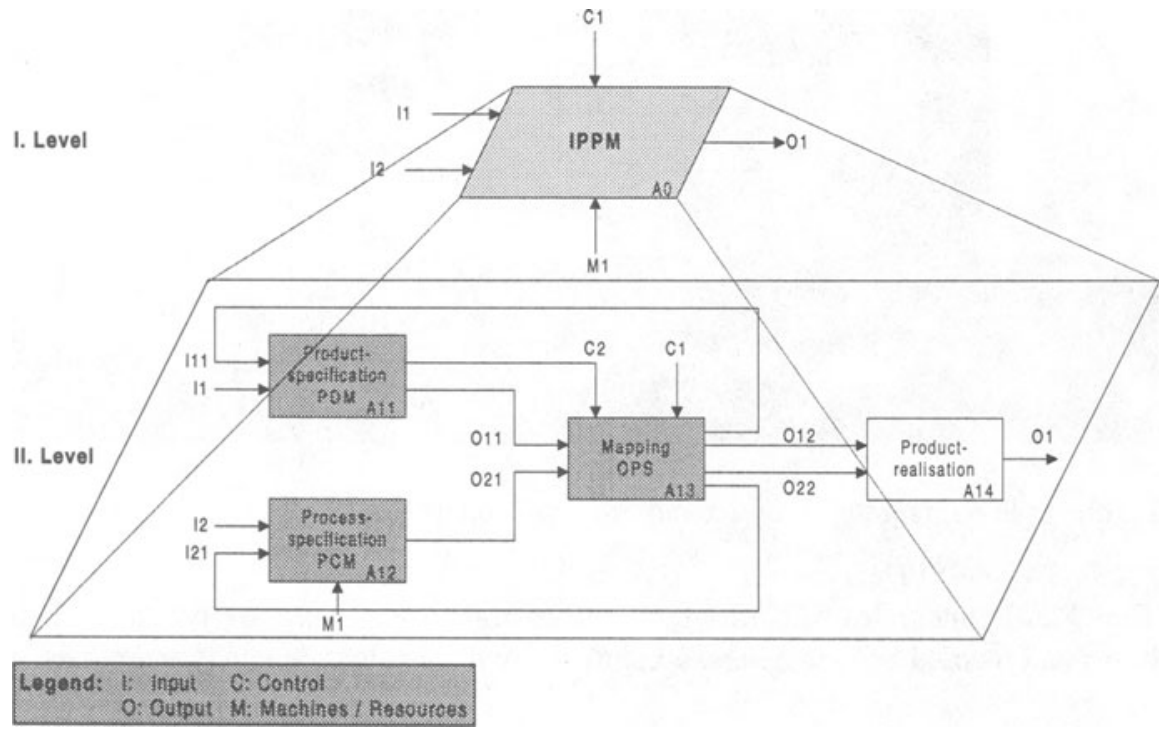

Figure 2: Interaction of Product and Process Model

Three types of information have to be covered by the IPPM:

product related data

process related data

product related process data

\section{Product related data}

The PDM has to cover several different types of information. All this data is allocated to and part of the product specification:

- Customer demands:

An internal or external customer specifies his product requirements, e.g. functionality and price. An internal customer may be for instance the marketing department. 


\section{- Performance specification:}

The customer demands are translated into the performance specification which is the basis for the product development.

- Process plan:

Process plan information like process sequence and estimated process times are important for the mapping of products to processes. This doesn't need to be detailed information, also a rough idea about possible manufacturing processes is sufficient in the first steps of product development.

\section{- Product parameters:}

The following parameters are seen as basic information concerning all products. Company and product specific parameters may be added.

- name, id, description

- dimension, form, tolerances, material

- classification, make-or-buy

- costs, quality aspects, error-rate, throughput-time

- number of components, number of items (over whole life cycle), output per time

Other information:

Other information may be different product versions and information about problems and their solutions. This information may be stored in the PDM to be available for other developers dealing with similar problems of other products.

\section{Process related data}

The PCM has to cover several process depending information. This data is independent of any products.

\section{process structure:}

The PCM enables the user of the system to describe different process structures. This covers process structures of different branches.

- manufacturing processes, service processes:

The PCM divides processes into manufacturing processes which are needed for producing the product and service processes which support the manufacturing processes. The manufacturing processes add value to the product in opposite to the service processes. Service processes are transport, quality control, maintenance and storage.

- Process sequences, process chains:

The PCM represents process sequences and process chains, e.g. manufacturing lines may be described by the system.

- Process parameters:

The following parameters are seen as basic information concerning all processes. Company specific process parameters may be added.

- name, id, description

- work, space, devices, tolerances, material

- classification, core competence 
- costs, quality, process reliability, process time

- capacity, quantity of use

- Machine parameters:

The following parameters are seen as basic information concerning all machines. Machine specific parameters may be added.

- name, id, description

- work space, devices, tolerances, material

- classification

- costs, quality, machine failures, process time, set-up time

- capacity, quantity of use

Other information:

The other information covers problems with processes and machines and their solutions.

\section{Product related process data}

The product related process data emerges from the conjunction of products and processes. All the following information has to be seen as process data concerning one special product. This information has to be allocated to both PDM and PCM inside the IPPM.

process sequence, process chain:

This describes which process sequence is used for producing one special product. This information may be enhanced by information about manufacturing lines.

- Process parameters:

The following parameters are seen as basic information concerning all processes. Company specific process parameters may be added.

- name, id, description

- work space, devices, tolerances, material

- costs, quality, process reliability, process time

- Machine parameters:

The following parameters are seen as basic information concerning all machines. Machine specific parameters may be added.

- name, id, description

- work space, devices, tolerances, material

- costs, quality, machine failures,

- process time, set-up time, throughput-time

Other information:

This covers all information concerning problems by the interaction of products and processes and their solutions.

For developing the IPPM the STEP standard (ISO 10303) is used as far as possible. A product model is nearly completely specified, but protocols concerning 
process models are not available. Therefore the PDM is strongly adapted to the ISO 10303, but the PCM is self developed in accordance to STEP.

\section{THE PRODUCT MODEL}

The Product Model (PDM) has the function to describe products, components and single parts in all possible variations. Given product specifications can be implemented into this model. Additionally new parameters describing the product can be defined. Also additional information relevant for the product description can be stored in the PDM. This could be the customer demands, where the customer specifies his product requirements, and the performance specification, where the customer demands are transferred into internal product requirements. Last but not least the PDM may contain various information about different development versions and problems during product development and their solutions.

Figure 3 shows the structure of the reference model of the PDM. It represents all relevant relations between product components describing the product structure and configuration. Depending on the type of relation the whole product and its components can be seen on different levels of detail and in different manufacturing steps.
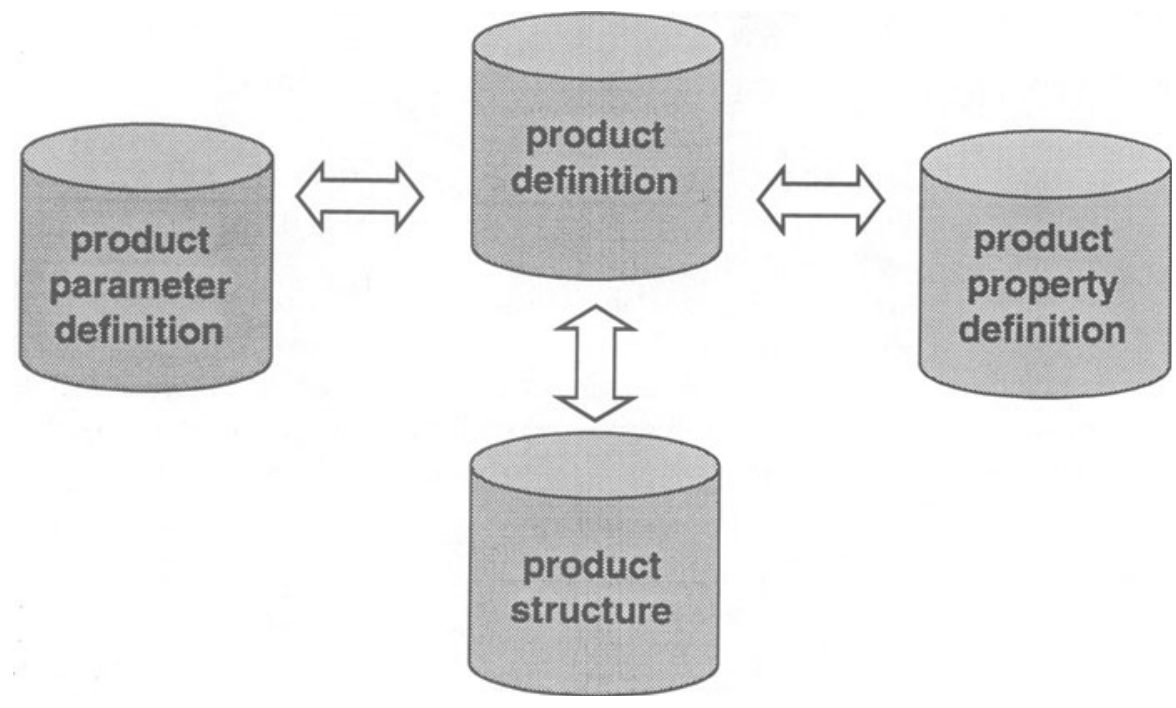

Figure 3: Reference model of the PDM

The entities of the product definition are describing the products, components and single parts. There are five main entities for specifying: 
the product,

the classification of products,

the product versions,

the definition of products and

the relations between product definitions.

The product structure specifies the structure of the product. The relations between products, components and single parts are described. Important is the relation between a product, component or single part concerning the result of the production process.

There are three main entities in the product structure which specify

the relations between similar products,

the assembly of components and

the manufacturing of components,

The product property definition specifies the properties of a product, component or single part regarding its shape, dimensions, tolerances and material.

The product parameter definition allows the user to define product specific parameters. Additionally these parameters may have certain default values specified in this schema. These default values may be changed during development and during the use of the product model in relation with processes.

\section{THE PROCESS MODEL}

The Process Model PCM is developed to model various process structures Additionally the PCM offers the possibility of specifying process chains and existing machines and manufacturing lines.

The PCM was developed in accordance to the Product Model. It mirrors the process structure with all relevant relations of sub processes used for describing the process. Dependent of the type of relation the process model may specify main processes and process chains or sub processes in different levels of detail. Figure 4 shows a schematic representation of the reference model. 

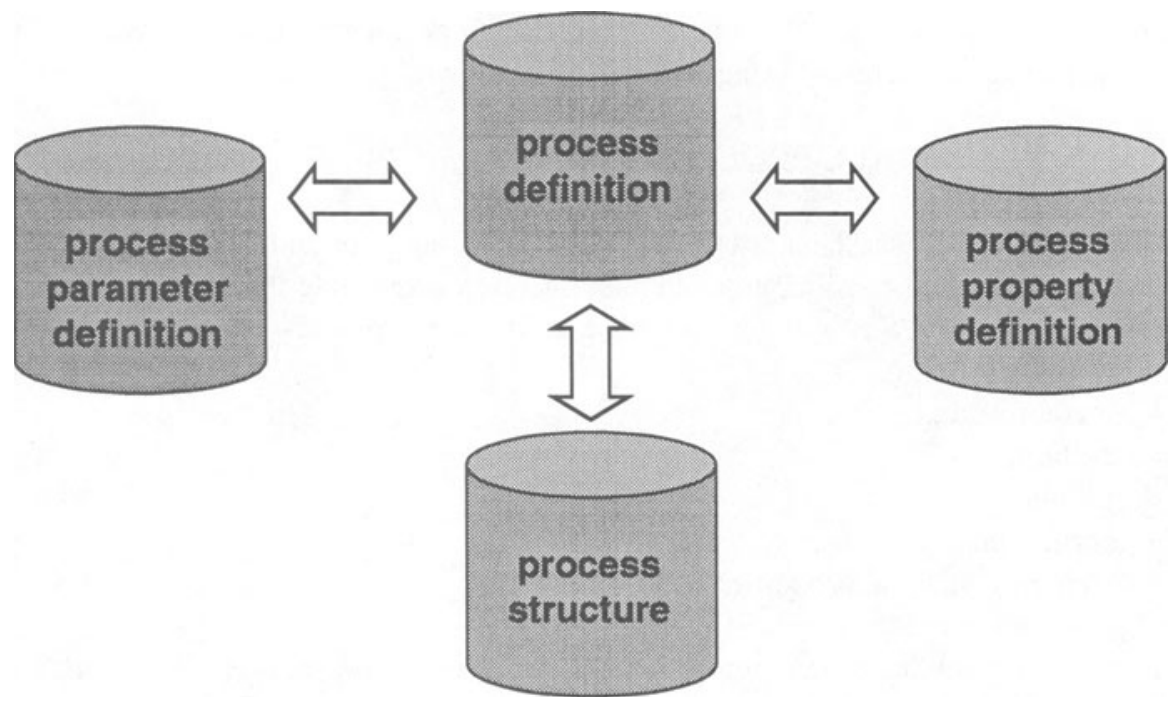

Figure 4: Reference model of the PCM

The entities of the process definition describe the processes and sub-processes. There are four main entities for specifying:

the process,

the classification of processes,

the process versions,

the definition of processes and

the relations between process definitions.

The process description is similar to the product description to enable the IPPM to map products to processes.

The process structure specifies the hierarchical structure of the process. There are three main entities in the process structure which specify

the relations between similar processes,

the manufacturing processes and

the service processes.

The process property definition specifies the properties and relevant parameters of a process. In relation with the entities of the process definition the parameters may be assigned to any process or sub-process. The definition of parameters may be done in the process parameter definition.

The process parameter definition allows the user to define process specific parameters. Additionally these parameters may have certain default values 
specified in this schema. These default values may be changed during development of the process model and during its use in relation with products.

\section{THE OVERALL PROCESS SCHEMA}

The Overall Process Schema OPS connects the product to suitable processes and production system configurations to manufacture or assemble its components. The top level of the OPS is built by the main manufacturing processes (DIN 8580):

- primary shaping,

- metal forming,

- cutting,

- joining,

- surface coating,

- changing material properties and

- special technologies.

In the next level these main processes are divided into sub-processes. These are for example for the manufacturing process 'joining':

- welding,

- soldering,

- clueing,

- screwing and

- riveting.

If necessary the sub-processes may consist of further sub-processes.

This process schema represents the set of possible processes which may be used to describe process sequences in the product model. On the other hand all existing processes in the manufacturing environment are captured by the OPS.

The proceeding in mapping a product description to possible manufacturing processes and production systems is as follows: The product model contains information about necessary manufacturing processes to produce the product. This could be on the top level of main manufacturing processes or on a detailed level of sub-processes. The system generates all possible solutions and offers a set of available machines or production systems ranked by suitable criteria like costs, expected quality, existing manufacturing lines, etc. Then the developer may select one of these results for further development.

\section{CONCLUSIONS}

The Integrated Product and Process Model (IPPM) is the core piece of a software system which supports the planning and configuration of production systems and the development of products in accordance to the manufacturing environment. The IPPM is divided into a Product Model (PDM) and a Process Model (PCM). Both are connected by an Overall Process Schema (OPS) which represents a hierarchical 
structure of existing or possible processes. The presented concept shows the principles of the models and of the mapping of products to processes.

PDM, PCM and OPS are open systems which may be adapted to special customer needs. This openness ensures that products and processes of different branches may be captured by the IPPM. Next step is the development of a suitable software environment for implementation of the system at production sites of companies from different branches (electronic components, entertainment electronics, tyre industry).

\section{REFERENCES}

ISO 10303: Product Data Representation and Exchange. INTERNATIONAL STANDARD ISO (1994)

DIN 8580: Fertigungsverfahren - Übersicht. Beuth-Verlag, Berlin (1973).

\section{ACKNOWLEDGEMENTS}

The results presented in this paper are elaborated in a research project funded by the European Commission under the research program Brite-Euram III (project $\mathrm{N}^{\circ}$ BE 3025).

We want to thank all partners in the consortium for their work in this project and for their contribution to the development of the Integrated Product and Process Model.

\section{BIOGRAPHY}

Prof. Dr.-Ing. Dr.-Ing. E. h. H. K. Tönshoff is full professor of production engineering at the University of Hannover, Germany. After receiving his Ph.D. degree in mechanical engineering in 1965 he worked as a designer, as technical manager and vice president in a machine tool company. In 1970 he became director of the Institute for Production Engineering and Machine Tools at the University of Hannover. In 1992 his work was honoured by bestowing a Dr.-Ing. E.h. degree on him. Since 1997 he is vice president of the International Institution for Production Engineering Research (CIRP).

Dipl.-Ing. M. Zwick, born in 1967, studied mechanical engineering at the University of Hannover, Germany. Since 1996 he is research engineer at the Institute for Production Engineering and Machine Tools, University of Hannover, where he is currently working in the division of manufacturing organisation. 